Visualizing Objects, Places, and Spaces: A Digital Project Handbook

\title{
Anchorhold Afference
}

Kelsey Dufresne

Published on: Feb 24, 2021

DOI: $10.21428 / 51$ bee781.a42d11ba

License: Creative Commons Attribution-NonCommercial-NoDerivatives 4.0 International

License (CC-BY-NC-ND 4.0). 


\section{Team}

Project Lead \& Designer: Kelsey Dufresne, Doctoral student in Communication, Rhetoric, and Digital Media, North Carolina State University

Colin Keenan and the VR Studio Team assisted with technology in the VR Studio at North Carolina State University's D. H. Hill Library.

\section{Project URL}

https://github.com/kvdufresne/AnchorholdAfference

\section{Project Abstract}

To make Julian of Norwich's poetic writings and realities as an anchoress more accessible to students, I created a virtual reality system, Anchorhold Afference, modeled after her anchorhold utilizing Unity and Oculus gaming applications and technologies and by relying on the technological supports offered with the NC State University Libraries System. Through this construction and implementation of VR, I was interested in:

1) How does VR technology help us better understand the positionality of anchoresses? and

2) What parallels can be found in the experiences of operating and employing VR systems and those of anchoresses?

\section{Visit the web version of this article to view interactive content.}

Anchorhold Afference

\section{Time Needed}

When did you begin this project? When did you complete this project?

Time Span: February 1, 2019 - present 
Length: 2+ years

\section{Outcomes}

What is the outcome of the project?

This project and critical making opportunity resulted in an operating virtual reality immersive experience that is modeled after anchorholds, much like that which Julian of Norwich may have lived in.

On a pedagogical level, this project centered the opportunity for student-led exploration and creation - to such a degree that an English literature student could work with code for the first time and generate a working product.

Now, this project is prioritizing presenting and sharing this work throughout digital humanities and literature conferences, while also publishing this piece to increase educational access and utility.

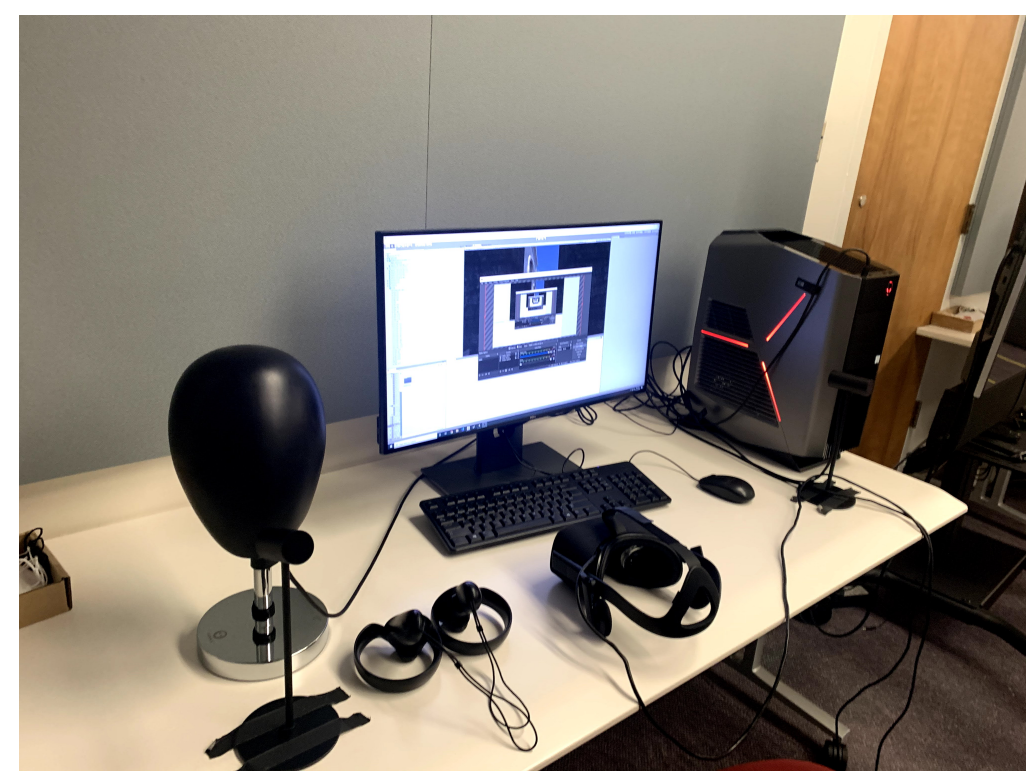

VR Studio, Workstation 1, at NC State University with Oculus and Unity.

\section{Resources}

What tools, resources, programs, or equipment did you use for this project?

- VR Studio 
- A significant portion of this project and corresponding work relied on the incredible accessibility of the VR Studio on NC State University campus that is open and available for all students to operate games and to also create VR systems. Furthermore, the staff affiliated with the studio greatly contributed technical and logistical assistance throughout the duration of the project, including helping it get started.

- Unity.

- This project was created within Unity, a gaming engine and development platform. All the more, Unity offers numerous helpful tutorials and avenues of support.

- TurboSquid

- As recommended by the VR Studio Team, this project was able to locate and incorporate assets, materials, and 3D models created and made available through TurboSquid. Because this project was unfunded, Anchorhold Afference relied on exclusively free assets or models and everything that I created on my own - including the anchorhold itself.

- $\underline{\text { Oculus }}$

- While created within Unity, this project was designed to operate with Oculus devices - namely the headset that users can wear and employ to be more fully immersed in the VR experience. With Oculus, this project is now exploring the capacities and infrastructure of the Oculus Mirror, pictured below.

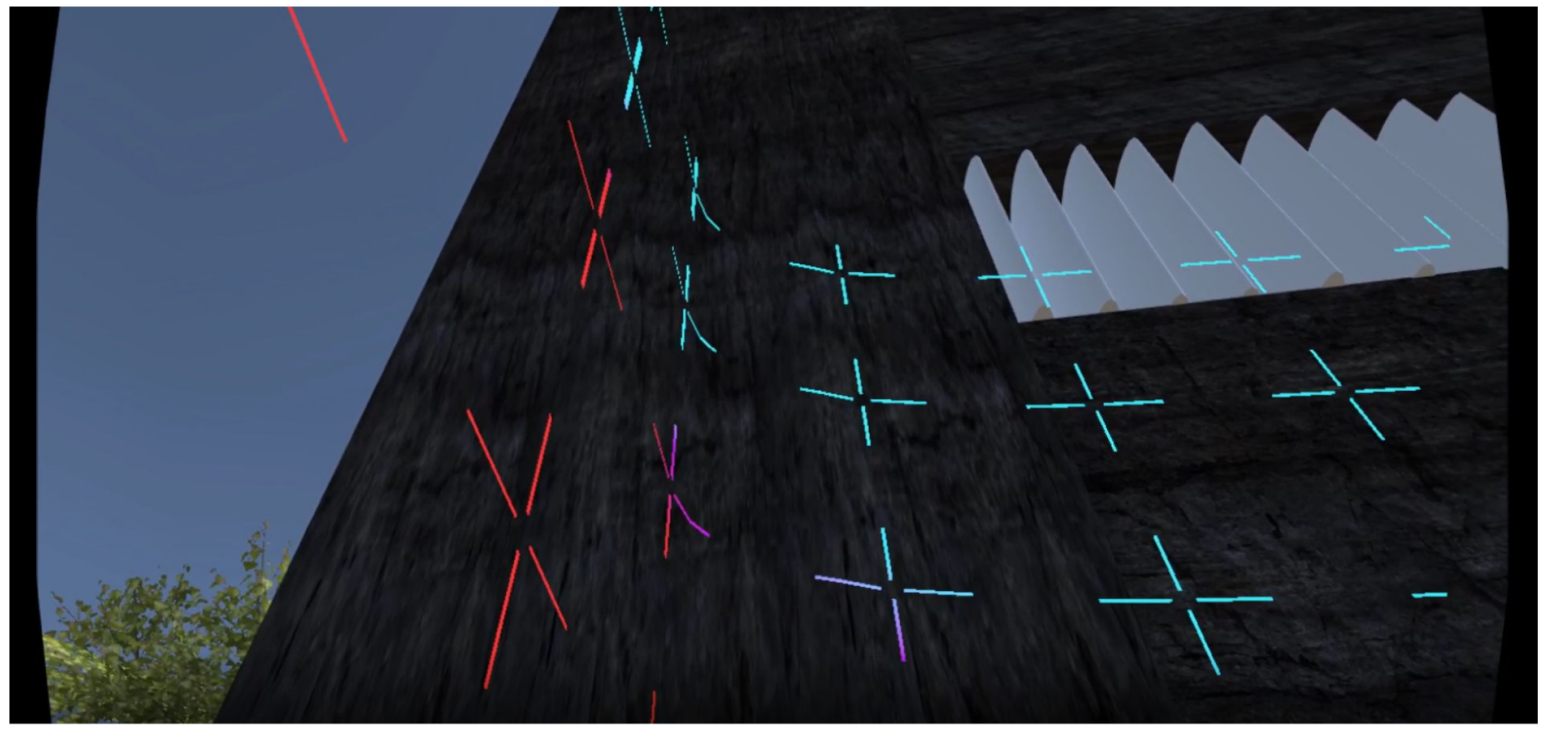
users from going beyond the confines of the VR space. 


\section{Funding}

Please describe any costs incurred for this project, and (if relevant) how you secured funding for these costs.

This project did not generate a cost in its development - largely due to the vast number and accessibility of tools, applications, technologies, spaces, and, most importantly, assistance offered by NC State University. For example, NC State University computers in the VR Studio come equipped with Unity and Oculus licensing and capacities.

\section{Workflow}

Please give an overview of the workflow or process you followed to execute this project, including time estimates where possible.

While enrolled in an Early Women Writers course at NC State University with Dr. Margaret Simon, I was drawn to Julian of Norwich's writing due to her biographical context and role as an anchoress. Like Julian of Norwich, anchoresses (or anchorites) practiced their religious devotion and sacrament through their lived confinement in anchorholds, which were small, cell-like spaces that have been identified as typically 12 square feet (Mary Wellesley.).

Not only was Julian of Norwich a poet and writer, but simultaneously was bound to her anchorhold. What might that mean? What was that like? How can we possibly imagine, envision, or understand what her life was like?

With these questions, I was inspired to create a 3D model of her anchorhold to strive to learn more with greater hopes that it could then inform students, such as myself, of the physical-spatial dimensions of anchorholds in relation to the anchoresses that occupied them. Thus, I envision that this project could be adopted into classrooms and made as accessible as possible to help facilitate a vast sharing of this resource across colleges and universities. All the more, I hope this project can serve as a pedagogical resource also for grade schools where technological devices, such as Unity and Oculus headsets, may not be as regularly available - if at all.

I, quite naively, aimed to accomplish this within a semester through VR technologies without any prior coding, computer science, or digital design experience. Prior to beginning the project, I was told it would take me a year to complete the project. I gave myself three months to create the 3D model, and have since then gone back and continuously revisited the project to critically engage with it. This extremely accelerated timeline was only possible due to the great support I received from the VR Studio at NC State University. From various individuals sitting with me and assisting in the coding and error problem solving, to connecting me to VR workshops on campus where I could work with other 
VR developers to participate in a community of practice - I was only able to create this project due to the support and system of technological access facilitated within the NC State University Libraries.

With incredible support, this project followed this generalized timeline over the course of three months:

- Learning Unity as a system.

- Creating basic geometric features - including the anchorhold.

- Implementing textures and assets to enhance visuals.

- Further learning Unity while developing the world by adding more trees as well as the ground to practice 3D construction and adding gravity to prevent the model from falling apart.

- Attempted to create a church structure (this was later discarded) in favor of a 3D model of a church from TurboSquid.

- Programming the camera so users would be positioned and confined within the anchorhold.

- Practicing and implementing Anchorhold Afference.

Following this creation, I have shared this project at conferences and am striving to increase the accessibility of this project beyond my university. Additionally, I recently began collaborating with Bryce Stout to study Anchorhold Afference as an immersive artifact. 


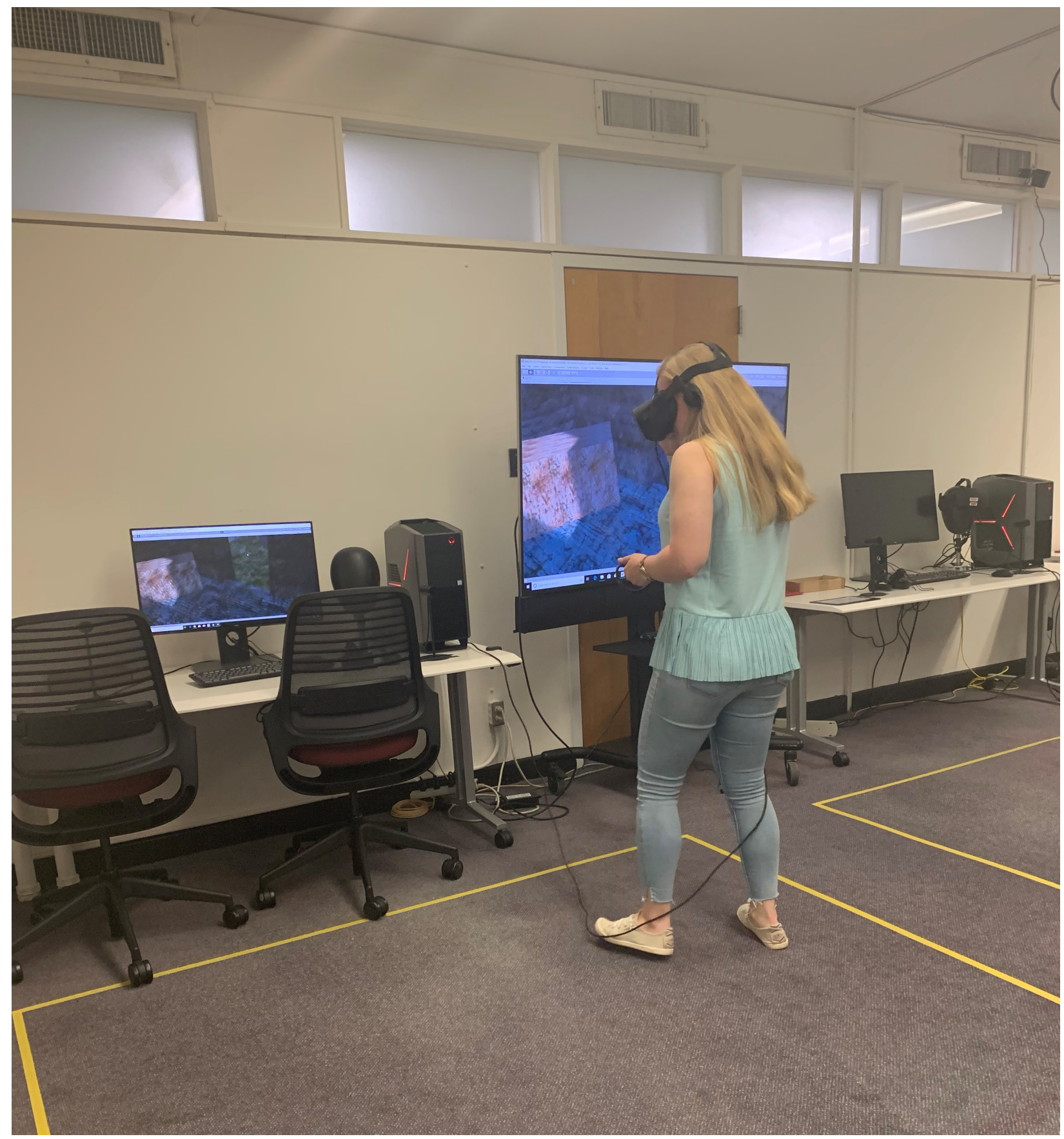

Student employing Anchorhold Afference, May 2019

\section{Challenges \& Opportunities}

What, if anything, changed between beginning your project and its current/final form?

I went into this project construction with very low expectations of what I could create. I think this absence of pressure for perfection charged the project forward and encouraged a more ludic 
exploration into VR design and construction. Yet, as I felt increasingly comfortable operating and creating within Unity, I felt compelled to add more elements than I originally intended. For example, I added trees and the church as additional visual measures, despite the fact that the user would only minimally see these features when employing Anchorhold Afference.

Beyond the tangible and technical project, I now want to approach the project through a critical lens with media and rhetorical studies. Thus, the literature and pedagogical orientation of the project are now being accompanied by more critical and theoretical frameworks than I had originally intended. More specifically, I want to offer Anchorhold Afference as a pedagogical, digital humanities tool and resource while also exploring it in the context of my own research as evidence in explorations of media, technology, and experiential learning.

Is there anything specific you wish you had known when beginning your project that might help other people to know?

While I entered into this project, and completed it, without ever really learning coding, I would encourage others to engage in projects and pursuits that they might otherwise avoid due to their technical-orientation. In considering how strongly reliant I was on the VR spaces and studio homed by my university, I would also strongly encourage others to consider what spaces, devices, technologies, and resources are available to help support learning and exploration.

\section{Visit the web version of this article to view interactive content.}

Interactive visualization of Anchorhold Afference created with PanoMoments.

\section{Next Steps}

Do you have any plans to follow up on this project or work on something similar in the future?

This project is still being explored, studied, and shared. In doing so, Anchorhold Afference will be all the more accessible and available for students, teachers, and the broad public via browser-based versions that can be accessed with any computer connected to Internet so anyone can learn more about Julian of Norwich. All the more, I want to continue exploring how this project can serve as model of digital humanities and scholarship capacities to help other students adopt similar methods - as well as how teachers can support such critical making opportunities in their classrooms. 


\section{Publications \& Presentations}

Dufresne, Kelsey. "Anchorholds, VR Technology, and the English Student on an Engineering Campus." Modern Language Association, Borrowed Tools for Digital Scholarship and Pedagogy. 2021. Toronto, Canada. [virtual]

Dufresne, Kelsey. "Critical Making in the Literature Classroom: Utilizing VR Technology to study Authorial Affect." Northeast Modern Language Association, Digital Humanities in Language and Literature Classrooms. 2021. Philadelphia, PA. [virtual]

Dufresne, Kelsey and Bryce Stout. "Anchorhold Afference: Virtual Reality, Radical Compassion, and Embodied Positionality." [in production] 